\title{
Analysis on the Development Trends and Differences of Scientific Research in Different Types of Universities
}

\author{
Zijuan Ren \\ School of Management, Jinan University, Guangdong, China \\ Email: rxin0312@126.com
}

How to cite this paper: Ren, Z. J. (2020). Analysis on the Development Trends and Differences of Scientific Research in Different Types of Universities. Open Journal of Social Sciences, 8, 182-199. https://doi.org/10.4236/jss.2020.86015

Received: March 26, 2020

Accepted: June 9, 2020

Published: June 12, 2020

Copyright ( 2020 by author(s) and Scientific Research Publishing Inc. This work is licensed under the Creative Commons Attribution International License (CC BY 4.0).

http://creativecommons.org/licenses/by/4.0/

\section{(c) (i) Open Access}

\begin{abstract}
In order to explore the differences in the academic research and academic entrepreneurship development models of different types of colleges, this paper obtained the longitudinal analysis data of 113 " 211 and provincial-columnconstructed colleges and universities" in China from 2007 to 2016, using repeated measurement analysis of variance to test the differences. Differences in academic research and academic entrepreneurship growth models are among universities with research strength, discipline structure, and regional types. The results show that: 1) There are significant differences in the academic research and academic entrepreneurship development levels of universities at different points in time, but overall they show a significant growth trend. 2) Colleges with higher academic research development level are universities with strong scientific research strength, comprehensive and technological universities with diversified disciplinary structures, and colleges with higher regional economic development level, while colleges with a faster rate of academic research growth have a general research strength. Agricultural, forestry and medical universities with a single discipline structure, and western and northeastern regions had low levels of economic development but supported by national policies. 3) The development level of academic entrepreneurship and academic research shows similar rules, but only the average scientific research strength, the diversified discipline structure, and the low level of regional economic development show a higher academic entrepreneurship growth rate. This article enriches the dynamic research of scientific research activities in colleges and universities, and provides a reference basis for the policy and long-term strategy formulation of colleges and governments.
\end{abstract}

\section{Keywords}

Academic Research, Academic Entrepreneurship, Repeated Measures 
Analysis of Variance, Growth Model

\section{Research Background}

Building world-class universities and disciplines with world competitiveness is an important task for the development of China's higher education at this stage. The government, the Ministry of Education, and all walks of life attach great importance to the development of scientific research in universities. In addition to the basic mission of talent training and scientific research, universities also tend to assume more social responsibilities, establish a close "triple spiral" relationship with the government and industry (Etzkowitz \& Leydesdorff, 2000), and actively participate in commercial activities in cooperation with industry (Van Looy et al., 2004). In recent years, with the expansion of academic entrepreneurship in universities, the government's “one-size-fits-all” policy encourages universities to attach importance to applied research and actively cooperate with enterprises to commercialize scientific research results. Funding has also gradually decreased in recent years, leading to the fact that colleges and universities are more inclined to the development of academic entrepreneurship due to financial pressure, which leads to the loss of their own characteristics and difficulty in exerting their own advantages. Therefore, it is necessary to explore the development models of academic research and academic entrepreneurship of different types of colleges, and then to discover the potential development trends of different types of colleges and bridge the development gap between colleges.

Different colleges and universities have different advantages in resources and abilities, which have significantly different influences on academic research and academic entrepreneurship. Scholars at home and abroad explore the influencing factors that may cause differences in the development of academic research and academic entrepreneurship at the individual, university, regional, and policy levels, and find the capabilities of researchers, whether they are public universities, regional characteristics, and the proportion of government or enterprise funding. All have a significant impact on the development of academic research and academic entrepreneurship in universities (Muscio et al., 2017; Wang et al., 2015; D'Este et al., 2013). For example, Bekkers believed that individual academic entrepreneurship achievements were positively correlated with scientific research ability, and the stronger the scientific research ability, the more scholars participated in academic entrepreneurship (Bekkers \& Freitas, 2008), and there were even more published papers at the same time (Sengupta \& Ray, 2017). Chang pointed out the significant differences in resources and abilities of different institutions of higher learning from the perspective of resource capability (Yuan et al., 2009). Science and technology universities have more opportunities to participate in academic entrepreneurship. Guo empirically analyzed that per capita GDP and output value of new industrial products were the main reasons for the inefficiency of scientific research activities (Guo et al., 2013). Although 
these studies pointed out the influence of different factors on the scientific research performance of colleges and universities, they only reflected the influence of single characteristics on academic research and academic entrepreneurship. The overall development mode of colleges and universities is the result of the comprehensive effect of multiple factors, and its own heterogeneous characteristics determine the orientation and development direction of colleges and universities. In addition, the descriptive analysis based on cross-section data of scholars can only reflect the average level of university development in a short time or at a certain time point (Chen et al., 2018), and cannot reflect its dynamic development law. With the development of time, colleges and universities have accumulated relevant experience and advantages in the process of academic research and academic entrepreneurship (Ju et al., 2018), and resources and abilities have been accumulated continuously to form the "Matthew effect" (Fiorentin et al., 2019). As a result, certain adaptability and tendency to scientific research activities have been generated, which makes colleges and universities show distinct growth modes (Zhou \& Li, 2018).

To realize the goal of the study, this paper chose to our country's higher education is representative of " 211 provincial department to build" colleges and universities as samples, repetitive measure the sample data of 2007-2016 research activities in colleges and universities, the use of repetitive measure Anova for academic research and academic entrepreneurship differences along with the change of time and different system of scientific research strength, and regional differences of college development model, and estimates the two dependent variables in the marginal effect of different situations, help the government and universities clear dynamic change pattern of differences between different types of colleges and universities, According to its own characteristics and advantages, the incentive mechanism and development strategy of academic research and academic entrepreneurship are selected and set, so as to realize the maximum development of scientific research advantages of universities.

\section{Theory Framework}

\subsection{Differences in Research Strength}

Scientific research strength is the ability of a university to explore unknown knowledge areas and produce innovative results, which depends on high-level researchers, sufficient research facilities and complete management mechanism. First of all, scientific research strength shows a huge impetus in knowledge innovation and technological innovation (Ho et al., 2016), which determines the significant difference in the quantity and quality of scientific research innovation achievements among different universities. For example, major research facilities and projects, such as large domestic research and development centers and laboratories, are built in top universities such as Tsinghua university and Peking University. Secondly, in terms of the actual situation of our country, the funds needed for the development of colleges and universities depend on the non-competitive appropriation of the government to a large extent. In contrast, 
the non-competitive funding of the state largely favors the universities with strong scientific research capabilities, which may lead to a certain degree of inertia in the universities with strong scientific research capabilities and lack of enthusiasm for academic entrepreneurship (Sun \& Zhu, 2019). In contrast, universities with less government non-competitive funding have more incentive to obtain external funding by applying for scientific research projects and developing the commercial value of applied technologies, and the resulting scientific research results have less correlation with knowledge innovation (Perkmann \& Walsh, 2009). Therefore, universities with average research strength may be more inclined to develop academic entrepreneurship due to the pressure of resources, and their enthusiasm for academic research is also weakened.

Scientific research strength, moreover, decide the quality of the knowledge creation and technological innovation, and the quality of the results is to distinguish the participation in academic entrepreneurship and a key feature of academic studies (Hewitt-Dundas, 2012), has the high quality of knowledge is more vulnerable to peer and journals approved and published, researchers to personal reputation and the development of academic career has larger significance. The more innovative the technological achievements have, the greater the potential commercial value, and the more inclined the universities are to participate in academic entrepreneurship activities to realize their economic value (Owen-Smith, 2003).

Finally, scientific research strength is often consistent with the "social reputation" of universities (Ambos et al., 2008), and universities with higher research strength often have higher social reputation. The academic entrepreneurship of colleges and universities is the marketization of scientific research achievements. Whether it is the licensing and transfer of patents, the spin-off of enterprises or other ACTS of cooperation with enterprises, the identity of colleges and universities is transformed into the seller of knowledge and technology. In the case of uncertain and inaccurate information, universities with good reputation are believed to produce more technological innovations worthy of investment, attract a large number of partners and technology buyers to universities, and reduce the start-up costs of universities (Fong et al., 2018). With the change of time, the interaction between universities with strong research capacity and the outside world in knowledge and information is constantly strengthened, and the innovation cooperation network formed provides powerful resources and technical support for the subsequent entrepreneurial activities (Di Gregorio \& Shane, 2003).

Therefore, universities with strong research strength are able to give consideration to both academic research and the development of academic entrepreneurship (Sengupta \& Ray, 2017), and both have developed rapidly in academic research and entrepreneurship, and the development gap between them and universities with average research strength is gradually increasing.

\subsection{Differences in Subject Structure}

In 2000 colleges and universities in China have experienced massive "build, ad- 
justment, cooperation and merger" reform, colleges and universities discipline layout and core positioning shows large differences, the subject matters of this difference is mainly manifested in the diversity, the types of key subject, resource input and institutional Settings, etc., many scholars according to cultivate discipline in colleges and universities, the type of advantage disciplines will be roughly divided into the integrated university, institute of technology, medicine and agriculture and forestry. Such differences in the internal discipline structure have a profound impact on the development of colleges and universities from two aspects: first, there are differences in the resources of colleges and universities with different discipline structures. Comprehensive universities in China is in the large-scale subject during the merger and scale by combining many small but powerful only branch of the school, the balanced development of the multidisciplinary and in the number of researchers, research funding, project number, and research facilities, equipment and so on all ahead of other types of colleges and universities. Some studies have pointed out that comprehensive colleges and universities of science and technology are obviously better than other three kinds of colleges and universities in obtaining competitive funding from enterprises (Zhao \& Liu, 2016), which indicates that science and technology colleges and universities have more opportunities to cooperate with enterprises, attach more importance to application-oriented research, and are more inclined to the development of academic entrepreneurship compared with other single-subject colleges and universities. However, the development of medical, agricultural and forestry colleges and universities depends more on the government's support and keeps a close relationship with the government. Therefore, these two types of universities are more inclined to the development of basic research, with less cooperation and exchanges with external enterprises, and have no advantages in the development of academic entrepreneurship.

In addition, there are significant differences in the difficulty of commercialization of scientific research achievements in different types of universities. Comprehensive colleges and universities have a multi-disciplinary structure and a balanced development of all kinds of disciplines. Polytechnic universities also belongs to the multi-disciplinary universities, but its core disciplines of engineering, and physical aspects of the research results compared with the results in engineering is more difficult to commercialize (Yang et al., 2007), so comprehensive and polytechnic universities with the discipline has technology innovation to transform the potential commercial value, but small differences in need internal coordination of the organization. Finally, medical technology invention is considered commercial possibilities of the highest professional (Powers \& McDougall, 2005), but for a long time medical invention faced with long development period, commercial investment, risk big, the overall level of its academic entrepreneurship is less likely than institute of technology and comprehensive universities, its growth model may be far lags behind that of other types of colleges and universities. 


\subsection{Regional Differences}

The political, economic, scientific and technological innovation, education, social environment, physical geography and other conditions of different regions have significant differences, which have different impacts on the talent gathering, resource acquisition, organizational structure and management system establishment of colleges and universities, so that the scientific research development of colleges and universities also shows corresponding regional differences. Good natural conditions, developed economy, education and social development level provide researchers with better career development opportunities and living conditions, which directly affect the talent accumulation and stability in the region (Mu \& Niu, 2014). At the same time, it provides a better market environment for the development of enterprises and the technology commercialization of universities, which is conducive to the formation of industrial clusters and innovation clusters (Adams, 2002).

At present, our country's economic development level is considered showed great regional differences, the eastern regional economic development speed, development level is high, the corresponding in the natural conditions and various social infrastructure such as education, health care and more complete, in attracting students with high quality, high level scientific research personnel and access to research funding has obvious advantages in (Wang, 2016); On the contrary, Xinjiang and Gansu, regions with poor natural environment and relatively backward economic development, are facing serious brain drain, and high-level scientific research talents flow to central and eastern regions. The development of academic research and academic entrepreneurship in colleges and universities depends on human resources, social environment and economic development, which leads to similar regional differences in academic development level and academic entrepreneurship level in colleges and universities.

In addition, the academic entrepreneurial activities of colleges and universities need a certain market environment to realize the commercialization value of the results, and the market environment of different regions in China has its own characteristics. The eastern region has a high level of opening to the outside world, forming more clusters of high-tech industries and innovation networks. The high demand for technological innovation provides a favorable market environment for the development of technology commercialization in universities (Liu \& Fu, 2010). However, the number of industries and universities in western and central regions is relatively small, the overall level of openness and innovation is backward, the motivation for academic entrepreneurship is insufficient, and the growth of academic entrepreneurship may gradually lag behind that of eastern and central universities due to the constraints of resources and environment.

\section{Research Design}

\subsection{Samples and Data Sources}

In order to explore the differences between academic research and academic en- 
trepreneurship development modes in Chinese universities and colleges, this paper selects the longitudinal data of 113 " 211 and provincial and ministerial co-built universities" in China from 2007 to 2016 for analysis, among which the information of military universities and affiliated hospitals is not included in the sample because it is not disclosed. These colleges and universities are all over the provinces in China, which are the focus of the development of higher education in each province. In addition, the data of this study are from the official data, mainly including the evaluation of Chinese universities published by the institute of Chinese academy of management sciences, the compilation of Chinese higher education science and technology statistics published by the ministry of education, and the patent information database of CNKI.

\subsection{Measurement}

1) Academic Performance (AP), as the basic mission of traditional universities, insists on the openness and publicity of research results, which are mainly manifested in journal papers, conference papers and books. Referring to the existing research and the actual situation of Chinese universities, this study selects the number of papers published in domestic and national journals of universities every year as the index to measure the academic research performance of universities (Ho et al., 2016). In order to satisfy the normality requirement of the repeated measurement data, the logarithm was taken.

2) Academic Entrepreneurship (AE), Academic entrepreneurship is also called by scholars as technology transfer, knowledge capitalization, patent licensing, patent transfer, school-run enterprises and entrepreneurial universities, etc. These definitions are mainly derived from the broad and narrow sense, but they all emphasize the commercial value of academic achievements. From the perspective of knowledge value chain creation, patent application belongs to the initial stage of academic entrepreneurship, which affirms and protects the potential commercial value of technological innovation (Siegel et al., 2003). From the perspective of the openness and sharing of university knowledge creation, the knowledge and technology created by universities should be shared by the society, and the application of patent is the privatization of the results and the embodiment of the potential commercialization motivation of universities or researchers (Blind et al., 2018). The higher the number of patent applications, the more inclined the university's research is to the application of research and the commercial development of research results (Wang \& Ruan, 2013). Referring to the research of Branco, the number of patents successfully applied by universities is used as an indicator to measure the academic entrepreneurship performance of universities (Ponomariov, 2013), and the data are from the information published in the patent database of CNKI. In order to meet the requirement of normality of repeated measurement data, the same logarithmic processing was performed on the patent data

3) Research Quality (RQ) is a classification variable of 0 or 1 . At present, there 
is no official institution in China to evaluate the scientific research strength of colleges and universities, and the academic community has different views on the research ability of colleges and universities. Some scholars use the government funded account for the proportion of the total funding to measure the level of college scientific research (Guo et al., 2013), but in fact, funding provided by the government funded by according to the scientific research strength of competitive and non-competitive fund in two parts, including a non-competitive fund proportion is larger, and the existing data and related research are unable to distinguish between the two parts. Therefore, this article combined with the college scientific research scale and results of comprehensive evaluation, Shanghai Jiaotong university for the academic level of colleges and universities on the evaluation results and the actual situation of domestic, to determine the "985 project" university as the research colleges and universities, the stronger power of "985 project" universities in general universities, variable with 1,0 , respectively, for the next phase of the construction of "double top colleges and universities" has more realistic significance.

4) Subject structure (Type), Subject structure determination of books borrowed from the original long Hong and $\mathrm{Wu}$ even the way of measuring, starting from colleges and universities have subject type, will be classified as a class of normal universities and comprehensive universities, values of 4 , has a value of 3 polytechnic universities and medical of agriculture and forestry university 2 and 1 , respectively, in other universities to 0 , other class contains classes and media of politics and law university (Yuan et al., 2009).

5) Region, According to the differences in the level of economic development and the research methods of most scholars, the 31 provinces in China are divided into three regions: "east, central and west", which are expressed by the classification variables of 1,2 and 3 .

\subsection{Research Method}

The main purpose of this study is to examine the differential distribution of growth modes of academic research and academic entrepreneurship in colleges and universities. The research sample is a longitudinal database established by the annual development data of each university, and the data show a great correlation in time. Using longitudinal data for analysis avoids the limitations of descriptive statistics in cross section data study, and combines the advantages of cross section data and panel data to enter the field of analytical research. It can not only analyze the dynamic change law of academic research and academic entrepreneurship in colleges and universities over time, but also analyze the differences of growth patterns of samples at different feature levels.

Because of the correlation between the repeatedly measured data, it violates the data independence requirement of the Anova, while the general Anova cannot explain the dynamic differences within the individuals, and may get the wrong conclusion. In addition, the analysis of variance of repeated measurements requires the spherically symmetric property of the variance matrix of data full football 
association, otherwise, the $\mathrm{F}$ value of the analysis of variance will be biased, increasing the probability of class I errors. Therefore, it is necessary to adjust the degree of freedom of time-related F statistics in the test. Stata14.0 software provides results of four correction coefficients, among which BOX test is the most conservative test result. If the test results are inconsistent with those of other three correction methods, the first Regular test result shall be used as the reference.

\section{Empirical Result Analysis}

\subsection{Development Mode Differences}

The variables of academic research performance and academic entrepreneurship performance, scientific research strength, discipline structure, region and time were included into the Anova model of repeated measurement, and then the distribution of the development differences of academic research in universities at different time points and the interaction between characteristics and time was analyzed. The analysis results are shown in the following Table 1 .

It can be seen from Table 1 that the goodness of fit $\mathrm{R} 2$ of the model after adjustment is about 0.90 , indicating that the goodness of fit of the model is good, and the explanatory variables put into the model can well explain the changes of the dependent variables. The four test values of the time factor (Year) were consistent and all significant at the significance level of $1 \%$, indicating that there were significant differences in academic research performance at each time point. In addition, the test results of time, region and discipline structure interaction items failed to pass the most conservative sphericity test, because there was a correlation between the repeated measurement data, the overly strict correction coefficient would conceal the differences between individuals, and other statistical results after correction were also statistically significant. Finally, the interaction between scientific research strength and time passed the most rigorous spherical test, $p$-value $=0.054<0.1$, and the test result was very robust. Therefore, the above test results explain that the development mode of academic research in colleges and universities depends not only on the change of time, but

Table 1. Repeated measurement analysis of variance and correction results of academic research performance.

\begin{tabular}{cccccccccc}
\hline \multirow{2}{*}{ Source } & Partial SS & df & MS & F & \multicolumn{4}{c}{ Prob $>$ F } \\
\cline { 7 - 10 } & & & & & & Regular & H-F & G-G & Box \\
\hline Year & 28.66 & 9 & 3.18 & 15.07 & 0.0000 & 0.0000 & 0.0000 & 0.0002 \\
Types\# Year & 11.59 & 36 & 0.32 & 1.52 & 0.0262 & 0.00486 & 0.074 & 0.2012 \\
Region\# Year & 9.08 & 27 & 0.34 & 1.59 & 0.0292 & 0.0524 & 0.0778 & 0.1965 \\
RQ\# Year & 4.24 & 9 & 0.471 & 2.23 & 0.0183 & 0.0352 & 0.0545 & 0.1384 \\
Residual & 190.04 & 899 & 0.211 & & & & &
\end{tabular}

1) $\mathrm{N}=1094 ; 2)$ Adj R-squared $=0.9415 ; 3$ ) Huynh-Feldt epsilon $=0.4644$; Greenhouse-Geisser epsilon $=0.3477$; Box's conservative epsilon $=0.1111$. 
also on the differences of research strength, discipline structure and regional factors among individuals.

As we can see from Table 2, the adjusted goodness of fit $\mathrm{R} 2$ of the model with academic entrepreneurship as the dependent variable is about 0.9011 , indicating that the model has a good goodness of fit and the explanatory variables put into the model can also well explain the changes of the dependent variables. The results of multivariate anova in the above table indicate that the four detection values of the time factor are consistent and $p<0.001$, indicating that the development level of academic entrepreneurship is significantly different at different time points, and that the government and universities attach great importance to academic entrepreneurship as well as the support of policies and resources may be of great significance to the sustained growth of academic entrepreneurship. Secondly, the results of the interaction term test of time and discipline structure did not pass the most conservative spherical test, but the statistical results after adjusting the degree of freedom of variables were statistically significant, indicating that the adaptability and tendency of different disciplines to academic entrepreneurship were different, and the development mode of academic entrepreneurship was also significantly different. Finally, the results of the four tests of the interaction between time and region and scientific research strength were consistent, which were statistically significant at $99 \%$ of the significance level, indicating that the growth model of academic entrepreneurship in universities was significantly dependent on regional factors and scientific research strength.

\subsection{The Development Mode of Universities with Different Strength}

The above test results only estimate the difference distribution of the scientific research performance of colleges and universities over time, so it is necessary to use the marginal effect graph to more intuitively show the difference of development modes among different individuals.

By Figure 1 can be seen, with the time development, academic research and academic entrepreneurship showed a rising trend, but in academic studies and

Table 2. Repeated measurement analysis of variance and correction results of academic entrepreneurship performance.

\begin{tabular}{ccccccccc}
\hline \multirow{2}{*}{ Source } & \multirow{2}{*}{ Partial SS } & df & MS & F & \multicolumn{5}{c}{ Prob > F } \\
\cline { 6 - 9 } & & & & & Regular & H-F & G-G & Box \\
\hline Year & 25.58 & 9 & 2.84 & 41.23 & 0.0000 & 0.0000 & 0.0000 & 0.0000 \\
Types\# Year & 11.89 & 36 & 0.33 & 1.75 & 0.0045 & 0.0334 & 0.0530 & 0.1452 \\
Region\# Year & 9.31 & 27 & 0.34 & 3.36 & 0.0000 & 0.0001 & 0.0005 & 0.0219 \\
RQ\# Year & 5.57 & 9 & 0.61 & 8.27 & 0.0000 & 0.0000 & 0.0000 & 0.0049 \\
Residual & 188.71 & 899 & 0.21 & & & & & \\
\hline
\end{tabular}

1) $\mathrm{N}=1094$; 2) Adj R-squared $=0.9011$; 3) Huynh-Feldt epsilon = 0.7088; Greenhouse-Geisser epsilon $=$ 0.52 ; Box's conservative epsilon $=0.1111$. 


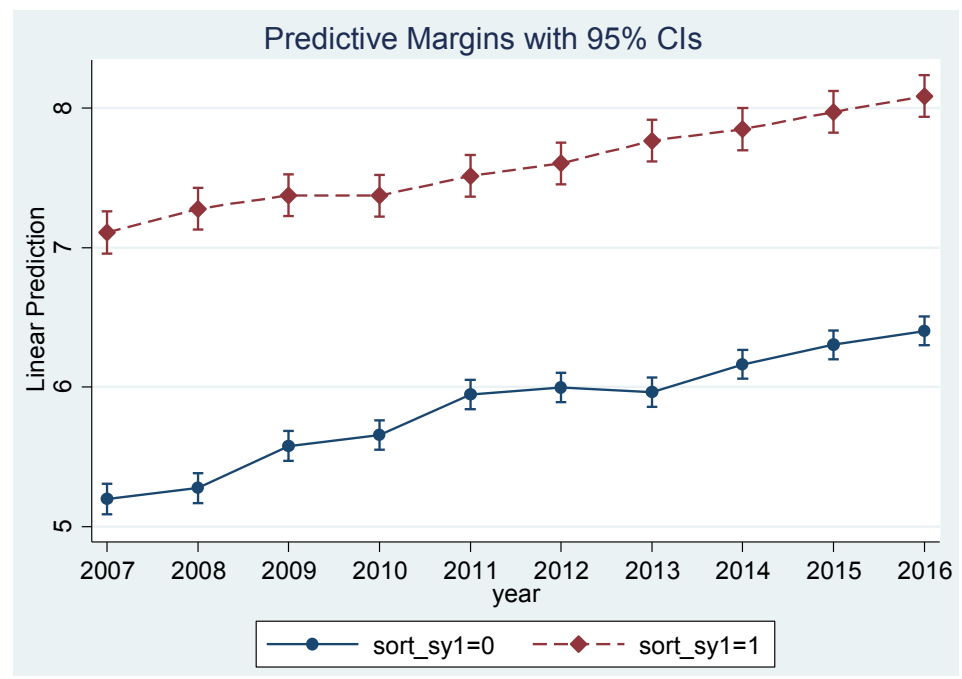

(a)

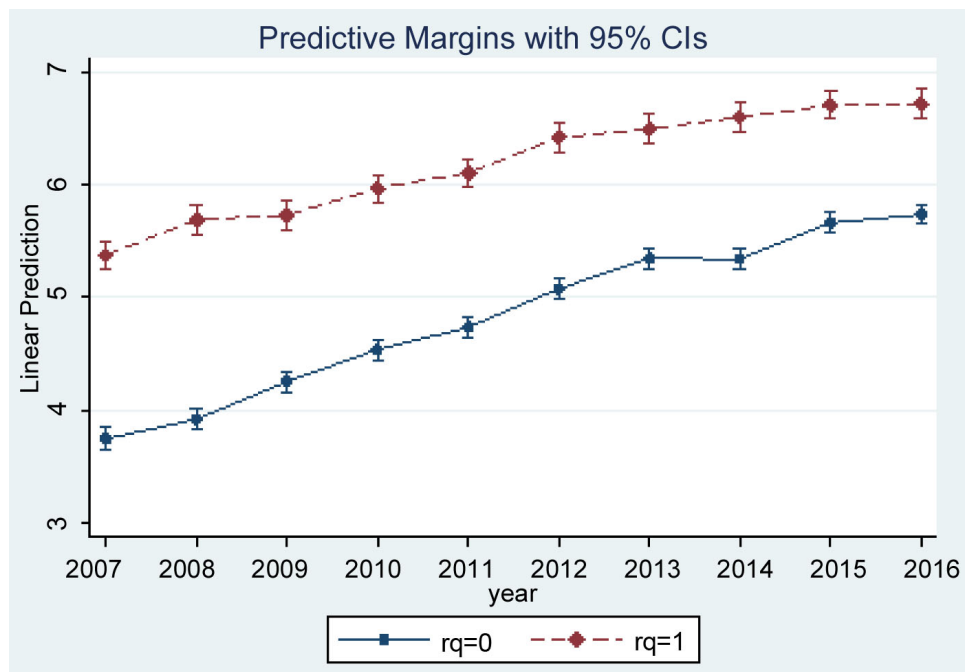

(b)

Figure 1. Marginal distribution of dependent variables under the interaction between research strength and time. (a) Study performance growth trend chart; (b) Patent growth trend chart.

scientific research strength in academic entrepreneurship development level are higher than that of scientific research strength weak colleges and universities, embodies the "Matthew effect" of the scientific research and development in colleges and universities, scientific research strength of colleges and universities in terms of resources and capabilities of cumulative effect make its level of academic research and business development occupy the leading position. In addition, universities with strong scientific research strength have advantages in seeking non-competitive public funding from the government, which can effectively transform existing scientific research resources into knowledge innovation recognized by the public and technological innovation with high commercial value. In addition, good reputation reduces the cost of academic entrepreneurship in universities and creates more development opportunities for them. 
Therefore, universities with strong research strength have more advantages in academic entrepreneurship and development of academic research, which is consistent with our previous theoretical derivation.

\subsection{Different Models of Colleges with Different Disciplinary Structures}

The above test results only estimate the difference distribution of the scientific research performance of colleges and universities over time, so it is necessary to use the marginal effect graph to more intuitively show the difference of development modes among different individuals.

As can be seen from Figure 2, academic research and academic entrepreneurship in colleges and universities with different systems and types show a

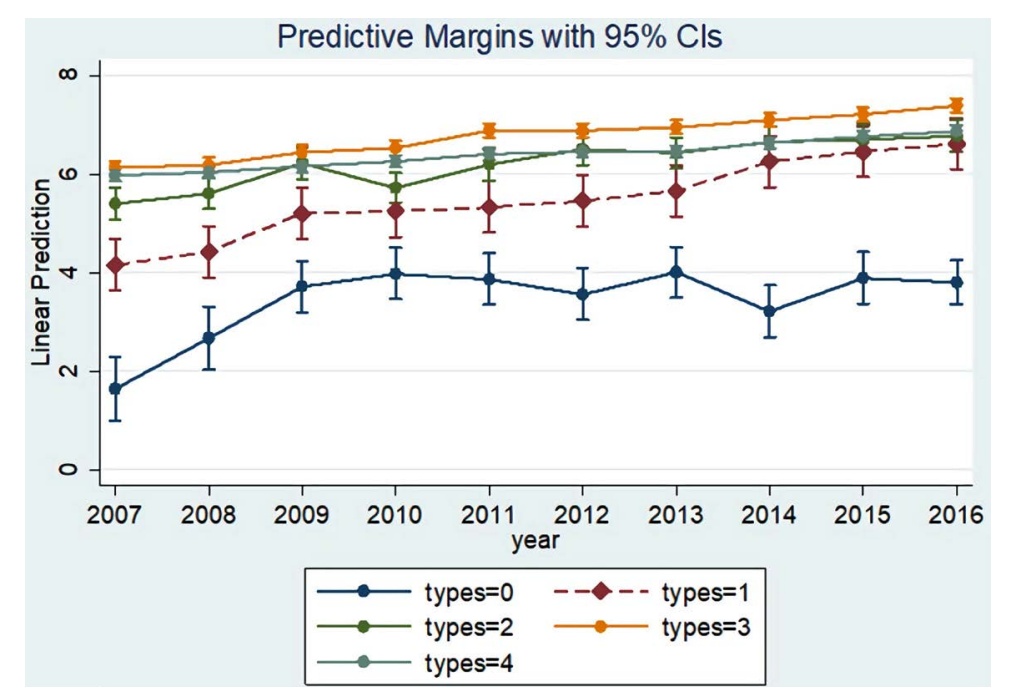

(a)

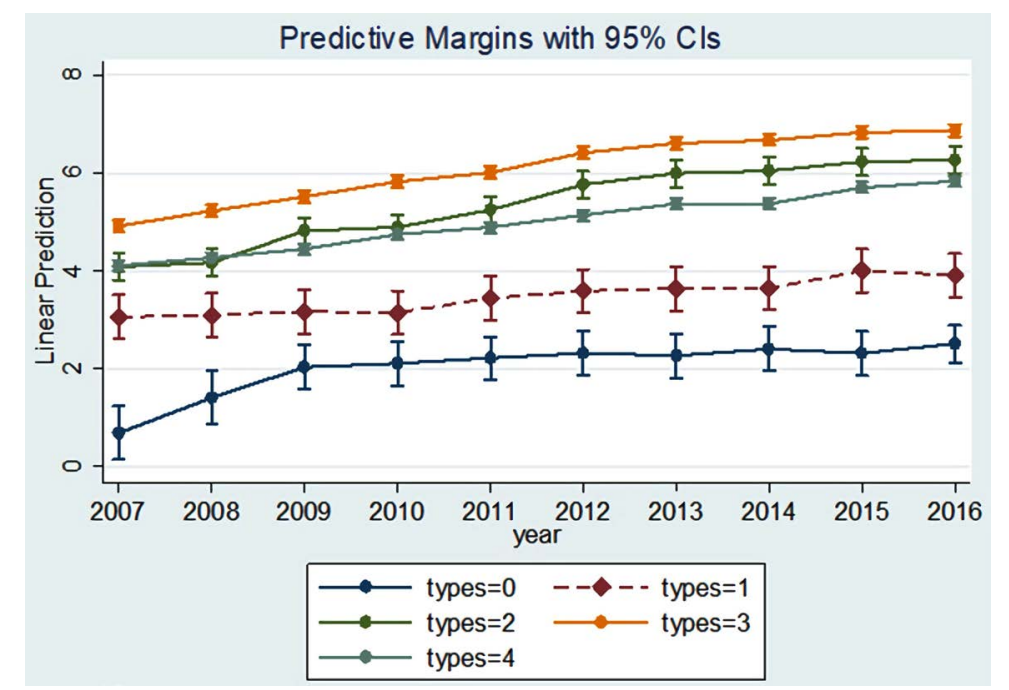

(b)

Figure 2. Marginal distribution of dependent variables under the interaction between discipline structure and time. (a) Study performance growth trend chart; (b) Patent growth trend chart. 
gradual growth trend over time, but various colleges and universities have different growth modes. First of all, the development level of academic research is from high to low: comprehensive $>$ science and technology $>$ agriculture and forestry $>$ medicine $>$ other categories. Among them, the growth of science and technology and comprehensive universities is relatively stable, but the performance level gap between them is gradually increasing. This may be because these two types of universities are multi-disciplinary universities, but the dominant disciplines of science and engineering universities and the balanced discipline structure of comprehensive universities are more advantageous and competitive in resource allocation. The academic research of agricultural and forestry colleges and universities tends to increase steadily after a short period of fluctuation. Medical colleges and universities have the largest growth range, and their development level is gradually in line with that of agricultural and forestry colleges and comprehensive colleges. The academic research development of other colleges (media and liberal arts) tends to be stable after two years of rapid growth, which may be due to the small number and scale of such colleges, whose research results are mainly in the form of non-academic journals, newspapers and books.

\subsection{Regional Differences in Growth Patterns}

According to the test in Figure 3, there are significant differences in the development modes of academic research among colleges and universities in different regions. Although there are large fluctuations in the central and northeastern regions, the overall trend is increasing. First of all, the eastern region has the largest increase in academic research, and its overall level of academic development has gradually surpassed that of the central and northeastern regions. This may be because in recent years, the eastern regional economic development level is high and growing faster, brought together a large number of high level talents

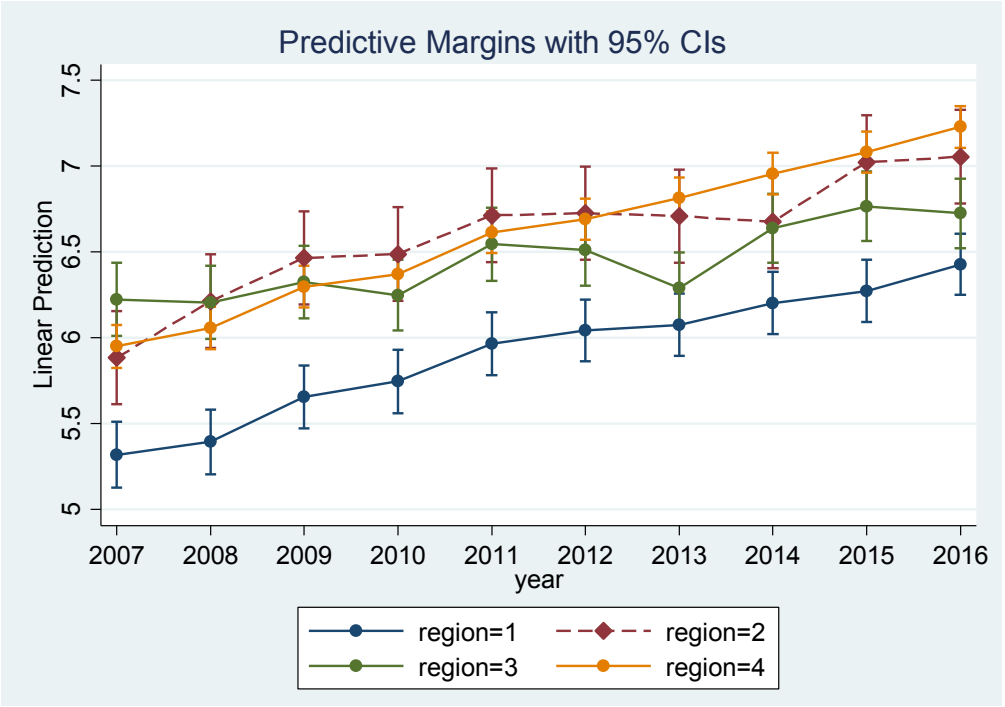

(a) 


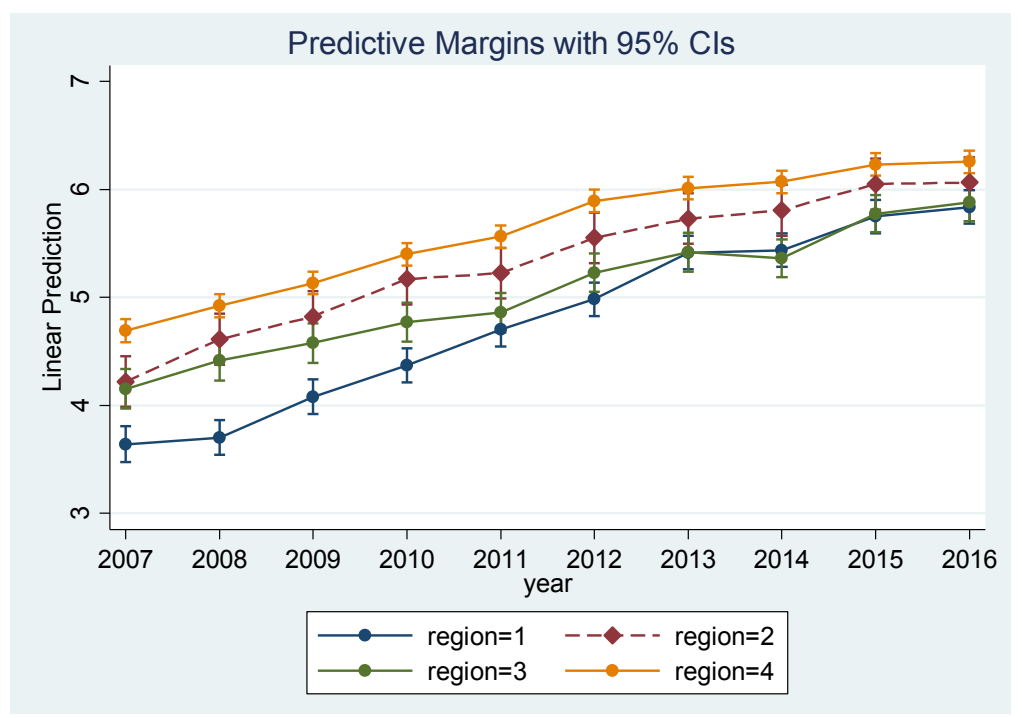

(b)

Figure 3. Marginal distribution of dependent variables under the interaction between region and time. (a) Study performance growth trend chart; (b) Patent growth trend chart.

and high quality students, create a higher level of opening and innovation environment, colleges and universities is to follow the rapid growth of economic development, academic research these factors contributed to the eastern area than other areas have a higher level of knowledge innovation. Secondly, the development level of colleges and universities in central and northeast China fluctuates obviously, but shows an overall growth trend. Western academic research in colleges and universities overall development level of the lowest but the biggest growth, the country has always been the strategy of "western development", "region economic zones" along "revitalization of the northeast old industrial base" development strategy, such as the western provinces invest a lot of resources and development opportunities, the introduction of a large number of talents, constantly through communication with central and eastern regions of the channel.

\section{Research Conclusion and Prospect}

In this paper, repeated measurements were made on the data of academic research and entrepreneurship conducted by 113 "211 project" from 2007 to 2016, and the trend of academic research and entrepreneurship development over time and the differences in growth patterns among universities with different characteristics were analyzed. Based on the above research, this paper makes the following findings:

1) With the development of time, the academic research and academic entrepreneurship performance of colleges and universities show an overall growth trend, and the growth rate of colleges and universities with different research strengths is significantly different. The development level of academic research and academic entrepreneurship of universities with strong scientific research strength is higher than that of universities with average scientific research 
strength, and the growth rate is lower than that of universities with average scientific research strength. This reflects the impact of the difference in scientific research strength of universities on the development model of academic research and academic entrepreneurship. Universities with strong scientific research strength are more inclined to take into account the simultaneous development and development of academic research and academic entrepreneurship and maintain a higher level of development. While the scientific research strength is lower, Universities in China face greater competitive pressures and show great tendency and development motivation for academic entrepreneurship, so they show a relatively fast development rate. In the future, the universities with average research strength may gradually surpass the universities with strong research strength while maintaining a high growth rate, and the "Matthew effect" among universities may gradually weaken. Therefore, it can be believed that gradually reducing the dependence of universities on government funding may stimulate the potential of academic research and academic entrepreneurship in universities, so that universities with strong scientific research strength can develop their own resources and capabilities to achieve faster growth.

2) The development model of academic research and academic entrepreneurship depends on different discipline structures. The academic research development level is from high to low: comprehensive class of science and technology > medicine $>$ other classes of agriculture and forestry. The academic entrepreneurship development level of colleges and universities is from high to low: science and technology $>$ agriculture and forestry $>$ comprehensive $>$ medicine $>$ other classes. This shows that the development of scientific research in different disciplines in China is unbalanced and the development level is significantly different. The multi-disciplinary structure can promote the development of cross-discipline, but the lack of the leadership of key disciplines will lead to the decline of the competitiveness among disciplines and the increase of the difficulty of resource management and allocation. And different disciplines for the difficulty of technology innovation, the cycle and transformation of achievements transformation risk factors such as may be the reason for the differences in academic entrepreneurship development mode, so the academic entrepreneurship should avoid homogeneity of different disciplines, for technology innovation more polytechnic universities to establish a perfect mechanism of technology transformation, improve the evaluation standard, stimulate vitality of technological innovation. Different innovation evaluation standards are adopted for different disciplines of comprehensive colleges and universities. Emphasis is placed on the cultivation of dominant disciplines, and the competition among disciplines is stimulated. Agricultural, forestry and pharmaceutical colleges and universities need to build a bridge of communication and cooperation between universities and enterprises based on more policy support, so as to reduce the obstacles in the entrepreneurial process.

3) The growth patterns of academic research and academic entrepreneurship are significantly different in different regions. The academic research and aca- 
demic entrepreneurship of colleges and universities in the eastern and western regions show a stable growth trend and a large range. There are obvious fluctuations in academic research in the northeast and central regions, which are significantly different from the situation that China's economic development level and academic development level are high in the east and low in the west. The growth rate of academic entrepreneurship in all regions is as follows: western > central > northeast $>$ eastern and the development level of academic entrepreneurship is similar to that of regional economic development. The academic entrepreneurship in each region shows a stable growth trend, and the differences between regions are significant, among which the western region has a large growth range. This suggests that the academic entrepreneurship is strongly influenced by regional environment, the western region in the natural environment and economic and social development are relatively backward, but with the support of policy, the development of information communication technology and transportation conditions, the western regional university academic entrepreneurship and academic studies had increased significantly, compared with the economic and environmental advantages in central area without showed rapid growth trend.

There are still some shortcomings in this study which need to be further explored in the future. In terms of the differences between the development modes of academic research and academic entrepreneurship in colleges and universities, only the influences of different research strengths, system types and regional types on the internal heterogeneity of individuals are explored. However, the development of colleges and universities is also influenced by the internal management mechanism, development strategies and external policies of colleges and universities. Future research should focus on the influence of internal management mechanism, resource allocation and management, external relations with the government and enterprises and other factors on the academic research and academic entrepreneurship development model of colleges and universities, so as to further explore the influence of these factors on the growth model of academic research and academic entrepreneurship in colleges and universities. At the same time, the limitation of this article is that it only conducts a descriptive analysis of scientific research output. Future research needs to include more samples and establish a comprehensive empirical model for interpretation.

\section{Conflicts of Interest}

The author declares no conflicts of interest regarding the publication of this paper.

\section{References}

Adams, J. D. (2002). Comparative Localization of Academic and Industrial Spillovers. Journal of Economic Geography, 2, 253-78. https://doi.org/10.1093/jeg/2.3.253

Ambos, T. C., Mäkelä, K., Birkinshaw, J., \& D’Este, P. (2008). When Does University Research Get Commercialized? Creating Ambidexterity in Research Institutions. Journal 
of Management Studies, 45, 1424-1447.

https://doi.org/10.1111/j.1467-6486.2008.00804.x

Bekkers, R., \& Freitas, I. M. B. (2008). Analysing Knowledge Transfer Channels between Universities and Industry: To What Degree Do Sectors Also Matter? Research Policy, 37, 1837-1853. https://doi.org/10.1016/j.respol.2008.07.007

Blind, K., Pohlisch, J., \& Zi, A. (2018). Publishing, Patenting, and Standardization: Motives and Barriers of Scientists. Research Policy, 47, 1185-1197. https://doi.org/10.1016/j.respol.2018.03.011

Chen, X. J., Xie, F., \& Dou, T. F. (2018). Substitution Effect or Complementary Effect?-The Influence of Commercial Knowledge Production on Academic Knowledge Production. Technical Economy, 37, 91-97, 130.

D’Este, P., Tang, P., Mahdi, S., et al. (2013). The Pursuit of Academic Excellence and Business Engagement: Is It Irreconcilable? Scientometrics, 95, 481-502. https://doi.org/10.1007/s11192-013-0955-2

Di Gregorio, D., \& Shane, S. (2003). Why Do Some Universities Generate More Start-Ups than Others? Research Policy, 32, 209-227. https://doi.org/10.1016/S0048-7333(02)00097-5

Etzkowitz, H., \& Leydesdorff, L. (2000). The Dynamics of Innovation: from National Systems and "Mode 2" to a Triple Helix of University-Industry-Government Relations. Research Policy, 29, 109-123. https://doi.org/10.1016/S0048-7333(99)00055-4

Fiorentin, F. A., Pereira, M., Suarez, D. V. (2019). As Times Goes by. A Dynamic Impact Assessment of the Innovation Policy and the Matthew effect on Argentinean Firms. Economics of Innovation and New Technology, 28, 657-673. https://doi.org/10.1080/10438599.2018.1557404

Fong, P. S. W., Chang, X. H., \& Chen, Q. (2018). Faculty Patent Assignment in the Chinese Mainland: Evidence from the Top 35 Patent Application Universities. Journal of Technology Transfer, 43, 69-95. https://doi.org/10.1007/s10961-015-9434-7

Guo, J., Wu, X. H., \& Wu, C. (2013). Performance Evaluation and Policy Enlightenment of Science and Technology Input-Output of Chinese Universities Based on Deatobit Model. Science and Technology Management Research, 33, 65-70.

Hewitt-Dundas, N. (2012). Research Intensity and Knowledge Transfer Activity in UK Universities. Research Policy, 41, 262-275. https://doi.org/10.1016/j.respol.2011.10.010

Ho, M. H.-C., Liu, J. S., \& Kuan, M. C. H. (2016). Torn between Academic Publications and University-Industry Collaboration. Research Evaluation, 25, 151-160. https://doi.org/10.1093/reseval/rvw001

Ju, X. N., Jin, J. Y., He, Y., et al. (2018). Matthew Effect in Higher Education and Its Countermeasures. China Electrochemical Education, 30, 12-16, 34.

Liu, Z. Z., \& Fu, Z. H. (2010). Analysis of Influencing Factors of Technology Transfer in Local Universities and Colleges. Scientific Management Research, 28, 26-29.

Mu, X. X., \& Niu, C. H. (2014). Evaluation of Talent Aggregation Effect Based on Grey Clustering-A Case Study of Six Provinces in Central China. Science and Technology Management Research, 34, 71-76.

Muscio, A., Ramaciotti, L., \& Rizzo, U. (2017). The Complex Relationship between Academic Engagement and Research Output: Evidence from Italy. Science and Public Policy, 44, 235-245.

Owen-Smith, J. (2003). From Separate Systems to a Hybrid Order: Accumulative Advantage across Public and Private Science at Research One Universities. Research Policy, 
32, 1081-1104. https://doi.org/10.1016/S0048-7333(02)00111-7

Perkmann, M., \& Walsh, K. (2009). The Two Faces of Collaboration: Impacts of University-Industry Relations on Public Research. Industrial and Corporate Change, 18, 1033-1065. https://doi.org/10.1093/icc/dtp015

Ponomariov, B. (2013). Government-Sponsored University-Industry Collaboration and the Production of Nanotechnology Patents in US Universities. The Journal of Technology Transfer, 38, 749-767. https://doi.org/10.1007/s10961-013-9301-3

Powers, J. B., \& McDougall, P. (2005). University Start-Up Formation and Technology Licensing with Firms That Go Public: A Resource-Based View of Academic Entrepreneurship. Journal of Business Venturing, 20, 291-311.

https://doi.org/10.1016/j.jbusvent.2003.12.008

Sengupta, A., \& Ray, A. S. (2017). University Research and Knowledge Transfer: A Dynamic View of Ambidexterity in British Universities. Research Policy, 46, 881-897. https://doi.org/10.1016/j.respol.2017.03.008

Siegel, D. S., Waldman, D., \& Link, A. (2003). Assessing the Impact of Organizational Practices on the Relative Productivity of University Technology Transfer Offices: An Exploratory Study. Research Policy, 32, 201-227. https://doi.org/10.1016/S0048-7333(01)00196-2

Sun, Z. Y. M., \& Zhu, F. W. (2019). Entrepreneurial Orientation, Environmental Factors and Entrepreneurial Performance of Chinese Universities. Science and Technology Management Research, 39, 97-103.

Van Looy, B., Ranga, M., Callaert, J., et al. (2004). Combining Entrepreneurial and Scientific Performance in Academia: Towards a Compounded and Reciprocal Matthew-Effect? Research Policy, 33, 425-441. https://doi.org/10.1016/j.respol.2003.09.004

Wang, Y. D., Hu, R. F., Li, W. P., et al. (2015). Does Teaching Benefit from University-Industry Collaboration? Investigating the Role of Academic Commercialization and Engagement. Scientometrics, 106, 1037-1055. https://doi.org/10.1007/s11192-015-1818-9

Wang, Z. B., \& Ruan, C. Y. (2016). Analysis of Regional Agglomeration of Human Resources in Chinese Universities and Its Macro Influencing Factors. Higher Education Research, 37, 13-21.

Yang, D. L., Wang, Q. Y., \& Meng, X. Q. (2007). Analysis of Influencing Factors of Derivative Enterprise Activities in Chinese Research Universities. Scientific Research, 23, 511-517.

Yuan, C. H., et al. (2009). The Influence of Chinese University System on Knowledge Transfer in Universities: An Analysis Based on Resource View. Science of Science and Management of Science and Technology, 30, 134-138.

Zhao, Q. N., \& Liu, J. (2016). Characteristics of Input and Output of Scientific Research in Colleges and Universities of Different Disciplines in China. Science and Technology Management Research, 36, 101-107.

Zhou, D., \& Li, Q. (2018). Empirical Test and Spatial Explanation of "Matthew Effect" of China's R\&D Resource Allocation. Technological Progress and Countermeasures, 35, 38-45. 